\title{
The lle585Val TRPV1 variant is involved in risk of painful knee osteoarthritis
}

\author{
Ana M Valdes, ${ }^{1}$ Gert De Wilde, ${ }^{2}$ Sally A Doherty, ${ }^{3}$ Rik J Lories, ${ }^{4}$ Frances L Vaughn, ${ }^{5}$ \\ Laura L Laslett, ${ }^{6}$ Rose A Maciewicz, ${ }^{7}$ Anushka Soni, ${ }^{8}$ Deborah J Hart, ${ }^{1}$ Weiya Zhang, ${ }^{3}$ \\ Kenneth R Muir, ${ }^{9}$ Elaine M Dennison, ${ }^{10}$ Margaret Wheeler, ${ }^{3}$ Paul Leaverton, ${ }^{5}$ \\ Cyrus Cooper, ${ }^{8,10}$ Tim D Spector, ${ }^{1}$ Flavia M Cicuttini, ${ }^{11}$ Victoria Chapman, ${ }^{12}$ \\ Graeme Jones, ${ }^{6}$ Nigel K Arden, ${ }^{8,10}$ Michael Doherty ${ }^{3}$
}

\begin{abstract}
- Additional data (Supplementary material) are published online only. To view these files please visit the journal online at (http://ard.bmj. com).
\end{abstract}

For numbered affiliations see end of article

\section{Correspondence to \\ Ana M Valdes, Department of Twin Research \& Genetic Epidemiology, King's College London, St Thomas Hospital, Westminster Bridge Rd, London SE1 7EH, UK; ana.valdes@kcl.ac.uk}

NKA and MD contributed equally

Accepted 1 April 2011 Published Online First 25 May 2011

\begin{abstract}
Objective To assess if a coding variant in the gene encoding transient receptor potential cation channel, subfamily $\mathrm{V}$, member 1 (TRPV1) is associated with genetic risk of painful knee osteoarthritis (OA). Methods The lle585Val TRPV1 variant encoded by rs8065080 was genotyped in 3270 cases of symptomatic knee 0A, 1098 cases of asymptomatic knee OA and 3852 controls from seven cohorts from the UK, the USA and Australia. The genetic association between the low-pain genotype lle-lle and risk of symptomatic and asymptomatic knee 0 A was assessed.

Results The TRPV1 585 Ile-lle genotype, reported to be associated with lower thermal pain sensitivity, was associated with a lower risk of symptomatic knee OA in a comparison of symptomatic cases with healthy controls, with an odds ratio (OR) of 0.75 (95\% Cl 0.64 to $0.88 ; p=0.00039$ by meta-analysis) after adjustment for age, sex and body mass index. No difference was seen between asymptomatic $0 \mathrm{~A}$ cases and controls $(\mathrm{OR}=1.02,95 \% \mathrm{Cl} 0.82$ to $1.27 \mathrm{p}=0.86)$ but the lle-lle genotype was associated with lower risk of symptomatic versus asymptomatic knee $0 \mathrm{~A}$ adjusting for covariates and radiographic severity $(\mathrm{OR}=0.73,95 \% \mathrm{Cl} 0.57$ to 0.94 $p=0.0136)$. TRPV1 expression in articular cartilage was increased by inflammatory cytokines (tumour necrosis factor $\alpha$ and interleukin 1). However, there were no differences in TRPV1 expression in healthy and arthritic synovial tissue.
\end{abstract}

Conclusions A genotype involved in lower peripheral pain sensitivity is significantly associated with a decreased risk of painful knee OA. This indicates a role for the pro-nociceptive gene TRPV1 in genetic susceptibility to symptomatic knee $0 \mathrm{~A}$, which may also be influenced by a role for this molecule in cartilage function.

\section{INTRODUCTION}

Osteoarthritis (OA) is the leading cause of physical disability in industrialised nations with severely impaired quality of life due to pain and loss of joint functioning. ${ }^{1}$ Pain is the major symptom of knee $O A$, and pain and disability in the presence of radiographic knee $\mathrm{OA}$ are the primary indications for total knee replacement. A patient who has severe knee pain and extensive radiographic evidence of $\mathrm{OA}$ is thought to have an 'obvious' explanation for the pain. ${ }^{2}$ Within the same patient, knee pain has been shown to be higher in the knee with greater $\mathrm{x}$-ray damage. ${ }^{3}$ Yet, a considerable number of individuals have advanced radiographic OA (Kellgren-Lawrence (K/L) scores $\geq 3$ ) in asymptomatic joints. ${ }^{2} 3$ For example, in the Framingham study only $19 \%$ of people with $\mathrm{K} / \mathrm{L}=2$ and $40 \%$ of those with $\mathrm{K} / \mathrm{L} \geq 3$ had knee pain on most days in the previous month, ${ }^{4}$ and in the Baltimore longitudinal study only $56 \%$ of cases with $\mathrm{K} / \mathrm{L} \geq 3$ had current pain. ${ }^{5}$

Thus, although a correlation between $O A$ joint damage and pain can be found, there is often discordance between the degree of structural change and the severity of pain, so disease severity defined exclusively by structural degeneration is inadequate.

One possible factor influencing pain severity in the presence of joint damage is a patient's individual sensitivity to pain, which has been shown to be strongly influenced by genetics. ${ }^{6}$ The transient receptor potential cation channel, subfamily $\mathrm{V}$, member 1 (TRPV1) is a thermosensitive channel present in a subpopulation of primary afferent sensory neurons and activated by noxious heat. 78 Notably, inflammatory stimuli sensitise TRPV1, a process that contributes to pain hypersensitivity in the context of tissue injury (see references in the article by Huang et al ${ }^{9}$ ). Preclinical studies have provided mounting evidence for a contribution of TRPV1 to pain in animal models of OA. Indeed, expression of TRPV1 is upregulated in the cell bodies of primary afferent fibres innervating the joint in the monosodium iodoacetate model of OA pain ${ }^{10}$ and systemic administration of TRPV1 antagonists blocks hyperalgesia and mechanical allodynia in these models. ${ }^{11}$ Expression of TRPV1, however, is not limited to neural cells but is also found in other cells in the joint, including chondrocytes, osteoclasts, osteoblasts and synovial fibroblasts, ${ }^{12-14}$ and thus the potential role of TRPV1 in OA is not limited to pain sensation.

An amino acid variant, Ile585Val encoded by rs8065080, in the TRPV1 gene has been reported to be associated with thermal pain sensitivity, ${ }^{15} 16$ with the Ile-Ile genotype corresponding to lower sensitivity to cold pain. The aim of this study was to determine whether there is a role for this genotype in risk of symptomatic knee OA compared both with healthy non-OA controls and with people with asymptomatic radiographic knee OA.

The expression of TRPV1 in human cartilage and synovium from patients undergoing arthroplasty as well as normal mouse cartilage has also been quantified to provide evidence that TRPV1 is present 
in joint tissues and may play a role in the process of cartilage breakdown leading to a damaged joint.

\section{SUBJECTS AND METHODS}

Data from five study cohorts from the UK, a study cohort in the USA and a study cohort from Australia were used. The study protocols for each cohort were approved by the local research ethics committees or institutional review board and all study participants gave fully informed consent to participate in genetic studies. For consistency between cohorts for the current study the radiographic definition of knee $\mathrm{OA}$ was a $\mathrm{K} / \mathrm{L}$ grade $\geq 2^{17}$ at the tibiofemoral compartment at one or both knees. Details on each of the study cohorts, recruitment, x-ray findings and pain assessment are included in the online supplementary section and the descriptive characteristics are shown in table 1. Because the Nottingham Case-Control Study did not have any asymptomatic subjects and the Hertfordshire Cohort Study had very few symptomatic subjects and these two UK study cohorts had similar age ranges, data for these two studies have been pooled for all analyses.

\section{Laboratory methods}

\section{Genotyping}

Genomic DNA was extracted from peripheral blood and DNA from the Genetics of Osteoarthrits and Lifestyle (GOAL) cohort was further whole genome amplified using standard protocols. Genotyping of the rs8065080 single nucleotide polymorphism (SNP) was carried out by Kbioscience Ltd, Hertfordshire, UK. SNPs were genotyped using the KASPar chemistry, a competitive allele-specific PCR SNP genotyping system. The polymorphism was in Hardy-Weinberg equilibrium in controls ( $p>0.05$ ) in all cohorts. Fifty-two samples were genotyped in duplicate and the concordance rate was $100 \%$.

\section{Gene expression experiments}

All procedures to obtain and work with human samples were approved by the ethical committee for clinical research at KU Leuven and patient informed consent was obtained. The informed consents preclude the analysis of the tissues for genomic analysis. Cartilage explants were obtained from patients undergoing total knee prosthesis surgery in the department of orthopaedics, University Hospitals Leuven. Pieces of cartilage were selected from visually healthy zones of the specimens. Cartilage explants from four different donors were used in triplicate cultures. Pieces were cultured in vitro in Dulbecco's modified Eagle's medium (DMEM) (Gibco, Carlsbad, California, USA) for 10 days in the presence or absence of interleukin (IL) 1 and tumour necrosis factor $\alpha(T N F \alpha) 10 \mathrm{ng} / \mathrm{ml}$ (Peprotech, Rocky Hill New Jersey, USA). Synovial biopsy specimens were obtained from patients undergoing arthroscopy of the knee for meniscal and cartilage injury in the department of orthopaedics or from patients with chronic arthritis undergoing diagnostic needle arthroscopy (one rheumatoid arthritis, two psoriatic arthritis) in the department of rheumatology, University Hospitals Leuven. Histological or flow cytometric analysis revealed that the control synovia had no signs of chronic inflammation. Synovial fibroblasts were collected and cultured as described by Lories et al. ${ }^{18}$ Primary cells were cultured in DMEM/10\% fetal bovine serum in the presence or absence of TNF $\alpha(0.1-10$ $\mathrm{ng} / \mathrm{ml})$ and human IL-1 $3(0.1-10 \mathrm{ng} / \mathrm{ml})$ for $2-24 \mathrm{~h}$.

Expression levels of TRPV1 were determined by quantitative real-time PCR using commercially available Taqman primerprobes sets (Applied Biosystems) for TRPV1 and housekeeping gene $\beta$-actin. Data were analysed with the $\Delta \mathrm{Ct}$ method relative to housekeeping gene $\beta$-actin for the synovial tissue samples and with a standardised method for independent biological replicates based on $\Delta \Delta \mathrm{Ct}$ with log transformation, mean centring,

Table 1 Descriptive characteristics of study subjects

\begin{tabular}{|c|c|c|c|c|c|c|c|}
\hline & \multicolumn{7}{|l|}{ Cohort name } \\
\hline & $\begin{array}{l}\text { Genetics of } \\
\text { Osteoarthritis } \\
\text { and Lifestyle }\end{array}$ & $\begin{array}{l}\text { Hertfordshire } \\
\text { Cohort Study }\end{array}$ & $\begin{array}{l}\text { Nottingham } \\
\text { Case-Control } \\
\text { Study }\end{array}$ & Chingford Study & TwinsUK Study & $\begin{array}{l}\text { Clearwater } \\
\text { Osteoarthritis } \\
\text { Study }\end{array}$ & $\begin{array}{l}\text { Tasmanian } \\
\text { Older Adult } \\
\text { Cohort }\end{array}$ \\
\hline Cohort acronym & GOAL & $\mathrm{HCS}$ & Nott & Chingford & TwinsUK & $\mathrm{COS}$ & TASOAC \\
\hline Country of origin & UK & UK & UK & UK & UK & USA & Australia \\
\hline \multicolumn{8}{|l|}{ Knee OA } \\
\hline Symptomatic & $\mathrm{n}=1199$ & $\mathrm{n}=86$ & $n=1703$ & $\mathrm{n}=68$ & $\mathrm{n}=45$ & $\mathrm{n}=83$ & $\mathrm{n}=86$ \\
\hline Age (years), mean (SD) & $68.4(7.2)$ & $65.3(2.8)$ & $68.7(8.9)$ & $65.7(5.8)$ & $57.5(7.2)$ & $65.6(8.3)$ & $65.0(7.2)$ \\
\hline Female (\%) & 46.9 & 44.3 & 55.3 & 100 & 100 & 66.7 & 58.50 \\
\hline BMI $\left(\mathrm{kg} / \mathrm{m}^{2}\right)$, mean (SD) & $31.2(5.4)$ & $29.7(5.4)$ & $29.7(5.4)$ & $26.7(3.4)$ & $27.9(4.5)$ & $29.1(5.1)$ & $31.3(6.3)$ \\
\hline$K / L \geq 3(\%)$ & 89.7 & 38.6 & 80.8 & 44.1 & 29.0 & 32.9 & 42.6 \\
\hline TKR (\%) & 94.8 & 9.3 & 90.3 & 23.5 & 26.7 & 24 & 0 \\
\hline TRPV1 585 lle-lle (\%) & 11.4 & 12.8 & 12.9 & 8.8 & 9.3 & 15.5 & 12.6 \\
\hline MAF (\%) & 35.1 & 37.2 & 36.9 & 38.2 & 31.4 & 33.8 & 35.1 \\
\hline Asymptomatic & $n=376$ & $\mathrm{n}=44$ & $\mathrm{n}=0$ & $\mathrm{n}=216$ & $\mathrm{n}=235$ & $\mathrm{n}=91$ & $n=136$ \\
\hline Age (years), mean (SD) & $69.0(6.7)$ & $65.2(6.4)$ & $\mathrm{N} / \mathrm{A}$ & $65.7(5.9)$ & $58.1(7.8)$ & $64.0(9.8)$ & $65.8(7.6)$ \\
\hline Female (\%) & 43.9 & 31.8 & $\mathrm{~N} / \mathrm{A}$ & 100 & 100 & 54.6 & 43.80 \\
\hline BMI $\left(\mathrm{kg} / \mathrm{m}^{2}\right)$, mean (SD) & $28.9(4.9)$ & $28.4(4.0)$ & $\mathrm{N} / \mathrm{A}$ & $26.2(4.4)$ & $26.7(4.9)$ & $26.1(4.7)$ & $28.1(4.3)$ \\
\hline $\mathrm{K} / \mathrm{L} \geq 3(\%)$ & 49.5 & 15.9 & N/A & 26.4 & 34.0 & 21.7 & 24.8 \\
\hline TKR (\%) & 0 & 0 & $\mathrm{~N} / \mathrm{A}$ & 0 & 0 & 0 & 0 \\
\hline TRPV1 585 lle-Ile (\%) & 14.4 & 11.9 & $\mathrm{~N} / \mathrm{A}$ & 11.7 & 17.1 & 17.6 & 18.4 \\
\hline MAF (\%) & 38.2 & 40.4 & N/A & 37.4 & 40.2 & 43.5 & 43.4 \\
\hline Unaffected & $n=743$ & $\mathrm{n}=542$ & $\mathrm{n}=728$ & $n=532$ & $\mathrm{n}=978$ & $\mathrm{n}=0$ & $\mathrm{n}=329$ \\
\hline Age years mean (SD) & $62.6(8.4)$ & $64.8(2.7)$ & $66.3(7.4)$ & $62.9(5.7)$ & $52.9(7.2)$ & $\mathrm{N} / \mathrm{A}$ & $61.8(7.5)$ \\
\hline Female (\%) & 49.9 & 50.1 & 57.4 & 100 & 100 & $\mathrm{~N} / \mathrm{A}$ & 47.9 \\
\hline $\mathrm{BMI}\left(\mathrm{kg} / \mathrm{m}^{2}\right)$ mean $(\mathrm{SD})$ & $27.1(4.4)$ & $26.2(3.8)$ & $26.6(3.9)$ & $24.7(3.6)$ & $24.5(4.0)$ & $\mathrm{N} / \mathrm{A}$ & $27.4(4.4)$ \\
\hline TRPV1 585 lle-Ile (\%) & 15.5 & 15.6 & 16.1 & 13.6 & 15.0 & $\mathrm{~N} / \mathrm{A}$ & 16.20 \\
\hline MAF (\%) & 38.5 & 38.5 & 37.8 & 38.1 & 37.8 & & 38.8 \\
\hline
\end{tabular}

BMI, body mass index; K/L, Kellgren-Lawrence; MAF, minor allele frequency; TKR, total knee replacement. 
and autoscaling as proposed by Willems et a ${ }^{19}$ for the in vitro experiments.

\section{Statistical analysis}

The association between the CC genotype at rs8065080 (Ile-Ile at TRPV1 codon 585) and knee OA (symptomatic and asymptomatic separately or together) versus controls was assessed by comparison of the frequency of the TRPV1 585 Ile-Ile genotype in knee OA cases and controls in unadjusted analyses and using a logistic regression model to adjust for covariates. The ORs from all cohorts were meta-analysed using a fixed-effects model. The natural logarithm of the odds ratio and its SE were estimated independently within each study adjusted for age, gender, body mass index (BMI) and in the case of symptomatic versus symptomatic cases also for radiographic severity (the maximum for radiographic $\mathrm{OA}(\mathrm{ROA})$ cases, the presurgical grade for the index knee in total knee replacement cases). For the TwinsUK Cohort in addition the estimates were corrected for the relatedness between individuals using a mixed-effects model with a robust estimate of the SE for the $\beta$ coefficient calculated by clustering over twin pairs.

Meta-analyses of data from these different cohorts were performed using R version 2.10.1 (the R Foundation for Statistical Computing http://www.r-project.org/). Heterogeneity was evaluated with $\mathrm{Q}$ statistic and $\mathrm{I}^{2}$. Random-effects models were not used as no heterogeneity was seen for any of the analyses $\left(\mathrm{I}^{2}<10 \%\right)$. Pooled analyses of all cohorts were also carried out, simply grouping all data in a single analysis.

\section{RESULTS}

The descriptive characteristics of the study cohorts including the Ile-Ile 585 genotype frequency and the number of control, symptomatic and asymptomatic knee OA cases available for each study are shown in table 1 .

We tested, using a crude meta-analysis (ie, simply comparing genotype frequencies), whether the Ile-Ile genotype was associated with knee $\mathrm{OA}$, and found that the Ile-Ile genotype at codon position 585 of the TRPV1 protein was associated with lower risk of knee OA (table 2). This association was stronger when only symptomatic knee OA cases were included (table 2) A much more modest and not significant difference was seen between asymptomatic OA cases and controls (table 2) but a comparison between symptomatic and asymptomatic $\mathrm{OA}$ gave a statistically significant result $\mathrm{OR}=0.76(95 \%$ CI 0.59 to 0.99$) \mathrm{p}=0.0378$ (table 2 ). We then carried out a pooled analysis combining all samples regardless of cohort of origin in a single analysis, but adjusting for covariates and found results to be extremely similar to those from the meta-analysis (table 2).

We further tested for association adjusting for age, sex and BMI in each of the study cohorts independently first (table 2) and meta-analysed them. We confirmed the association with knee $\mathrm{OA}$ overall (figure $1 \mathrm{~A}$ ), the stronger association between symptomatic $\mathrm{OA}$ versus controls (figure $1 \mathrm{~B}$ ) and the lack of association between asymptomatic $\mathrm{OA}$ and controls (figure 1C).We also investigated whether there was a difference between asymptomatic and symptomatic knee OA cases adjusting for age, sex, BMI and radiographic severity and this difference achieved statistical significance (figure $1 \mathrm{D})(\mathrm{OR}=0.74,95 \% \mathrm{CI}$ 0.57 to $0.97 \mathrm{p}=0.014$ ).

\section{Gene expression}

Gavenis et al demonstrated that TRPV1 is expressed in articular chondrocytes, but expression decreases with dedifferentiation of the cells upon in vitro culture and passaging. ${ }^{12}$ Here we evaluated the effects of the proinflammatory and cartilage destructive cytokines IL-1 and TNF $\alpha$ on gene expression of TRPV1 in articular cartilage explants obtained from patients with endstage knee $\mathrm{OA}$, undergoing prosthesis surgery. Exposure to IL-1 and TNFo in vitro significantly upregulated TRPV1 expression in challenged cartilage (average relative expression $3.34(95 \%$ CI 2.55 to 4.37 ) versus 1 ( $95 \%$ CI 0.68 to 1.48$)(n=4)$ (figure $2 \mathrm{~A}$ ). Expression of TRPV1 in synovial fibroblasts from patients with rheumatoid arthritis and $\mathrm{OA}^{14}$ and in the synoviocyte cell line SW $982^{20}$ has been shown to be upregulated by TNF $\alpha$. Despite this, we found no difference in the expression of TRPV1 in synovial tissue biopsy specimens between patients without, and those with, inflammatory arthritis, suggesting that proinflammatory cytokines have differential effects on synovial tissue and articular cartilage (average relative expression compared with $\beta$-actin $(\times 1000) 2.48(95 \% \mathrm{CI}-1.80$ to 6.00$)$ ) versus 3.47 ( $95 \% \mathrm{CI}-1.37$ to 8.29$)$ ) ( $\mathrm{n}=3$ per group) (figure $2 \mathrm{~B}$ ). Given the difference between our observations in articular cartilage and synovial tissue, we further examined the regulation of TRPV1 expression in normal human synovial fibroblast in the presence or absence of IL-1 and TNF $\alpha$. In contrast to the results reported for SW982 cells, we found no upregulation or downregulation of TRPV1 in synovial fibroblasts treated with IL-1 or TNF $\alpha$ for $30 \mathrm{~min}$ to $24 \mathrm{~h}$ (dose range $0.1-10 \mathrm{ng} / \mathrm{ml}(\mathrm{n}=3)$ (data not shown).

Table 2 Association between the TRPV1 585 lle-lle genotype and symptomatic or asymptomatic knee osteoarthritis (OA) in a crude meta-analysis and in pooled analysis

\begin{tabular}{|c|c|c|c|c|c|c|}
\hline Groups compared & Sample size & $\begin{array}{l}\text { Summary OR } \\
\text { (95\% Cl) (crude } \\
\text { Mantel-Haenzsel) }\end{array}$ & $\begin{array}{l}\text { p Value } \\
\text { meta-analysis }\end{array}$ & $\begin{array}{l}\text { Heterogeneity }{ }^{2} \\
\text { p(Cochran's 0) }\end{array}$ & $\begin{array}{l}\text { Pooled analysis } \\
\text { OR }(95 \% \mathrm{CI})\end{array}$ & $\begin{array}{l}\text { p Value pooled } \\
\text { analysis }\end{array}$ \\
\hline $\begin{array}{l}\text { Any knee } 0 \mathrm{~A} \text { versus } \\
\text { controls }\end{array}$ & $\begin{array}{l}4368 \text { cases, } \\
3852 \text { controls }\end{array}$ & 0.83 (0.73 to 0.95 ) & 0.0073 & $R^{2}=0 \% \mathrm{p}(0)<0.39$ & $0.84(0.72 \text { to } 0.98)^{*}$ & $<0.0277^{*}$ \\
\hline $\begin{array}{l}\text { Asymptomatic knee } 0 \mathrm{~A} \\
\text { versus controls }\end{array}$ & $\begin{array}{l}1098 \text { cases, } \\
3852 \text { controls }\end{array}$ & 0.99 (0.81 to 1.22 ) & 0.93 & $R^{2}=0 \% \mathrm{p}(0)<0.67$ & $1.01(0.78 \text { to } 1.31)^{*}$ & $<0.92^{*}$ \\
\hline
\end{tabular}

ORs refer to the risk of individuals carrying the TRPV1 585 lle-lle compared with Val-Ile and Val-Val individuals.

${ }^{*}$ Adjusted for age, sex and body mass index (BMI).

${ }^{\dagger}$ Adjusted for age, sex, BMI and Kellgren-Lawrence grade.

${ }^{\ddagger}$ All estimates are also adjusted for relatedness between twins. 
A

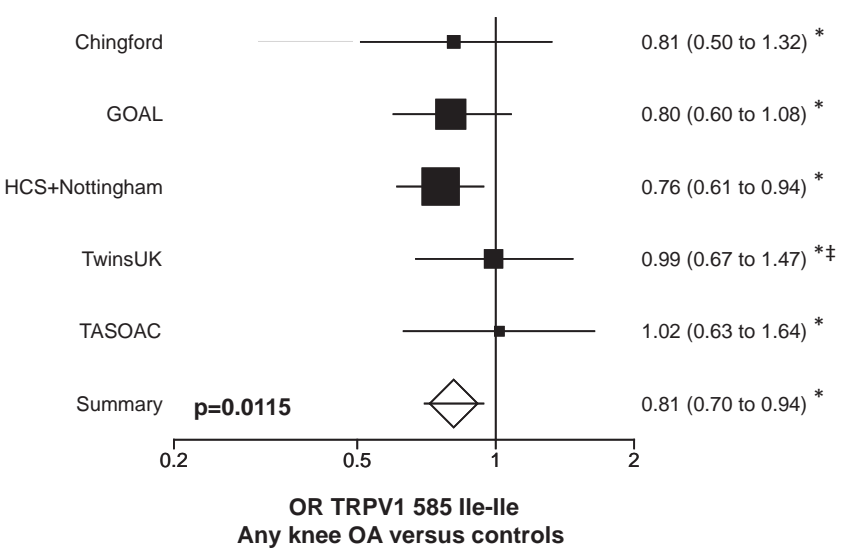

C

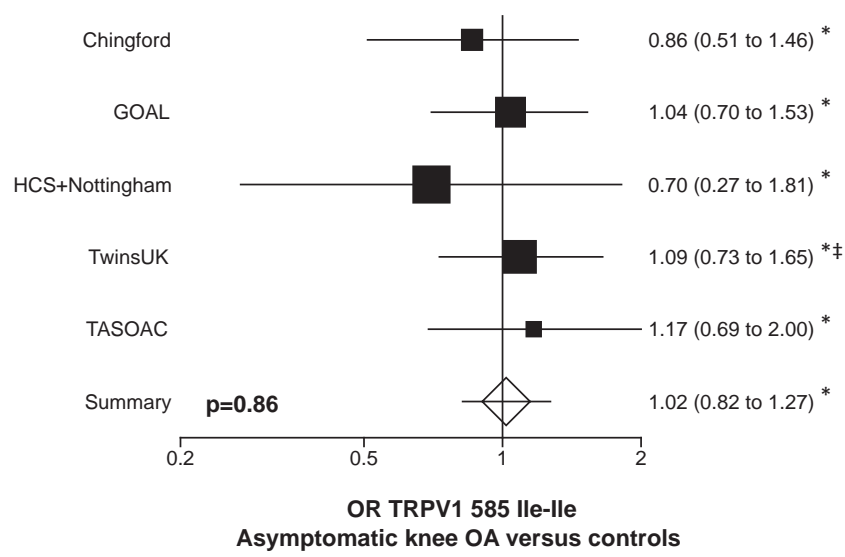

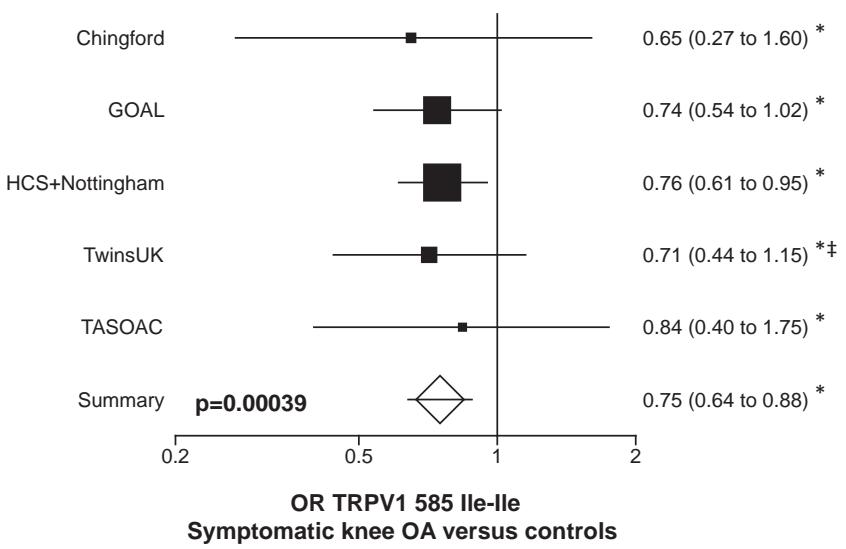

D

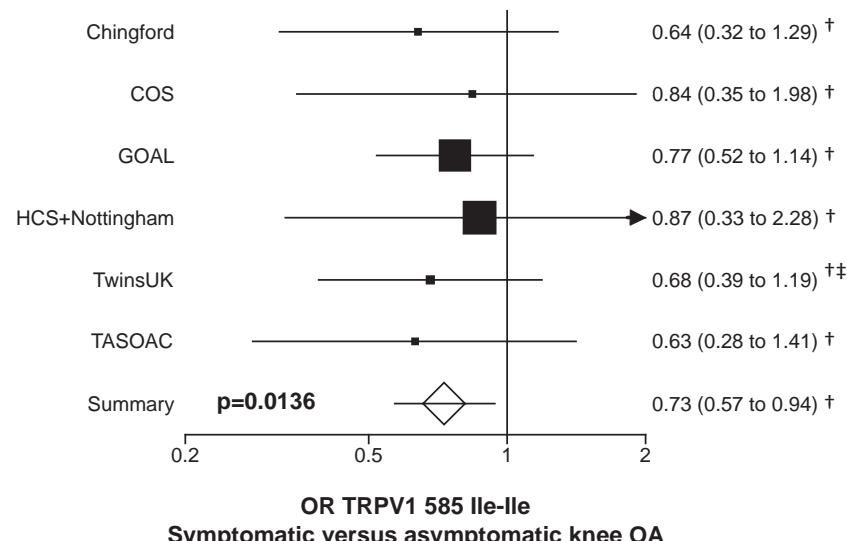

Symptomatic versus asymptomatic knee $\mathrm{OA}$

Figure 1 Forest plot showing study specific estimates for the association between the lle-lle TRPV1 585 genotype and (A) knee osteoarthritis $(O A$; regardless of symptoms) versus controls; (B) symptomatic knee $0 A$ versus controls; $(C)$ asymptomatic knee $0 A$ versus controls;

(D) symptomatic versus asymptomatic knee OA. * OR estimates are adjusted for age sex and body mass index (BMI); †OR estimates are adjusted for age, sex, BMI and Kellgren-Lawrence grade; ¥OR estimates are adjusted for relatedness between twins. COS, Clearwater Osteoarthritis Study; GOAL, Genetics of Osteoarthritis and Lifestyle; HCS, Hertfordshire Cohort Study; TASOAC, Tasmanian Older Adult Cohort.

\section{DISCUSSION}

In this study we report for the first time an association between the TRPV1 gene and risk of symptomatic knee OA. We found a significant association between an amino acid variant in the TRPV1 molecule, which previously had been implicated in pain sensitivity, with the risk of symptomatic but not asymptomatic radiographic knee OA. The observation that the genotype implicated in lower pain sensitivity is significantly associated with a lower risk of painful OA agrees with our initial hypothesis. After adjustment for confounding variables (age, sex, BMI and radiographic severity) the difference between symptomatic and asymptomatic OA also achieves statistical significance, further supporting our initial hypothesis.

We note that there are some study limitations. We only investigated the role of a single variant in the TRPV1 gene and other SNPs in TRPV1 may show a stronger association, which may be identified by finer mapping of this gene. Moreover, our data apply only to subjects of European descent. Differences in the strength or even the presence of genetic associations have been reported between Asian and European patients (eg, Valdes et $a^{21}$ ), therefore it is possible that this variant may not be associated in other ethnic groups.
It is well recognised that there is an important genetic contribution to the development of $\mathrm{OA}$, with heritability estimates in the order of $40-60 \%$ for knee, hip and hand OA. ${ }^{22}$ However, most studies investigating genetic associations with OA have focused on structural change in joint tissues rather than the clinical presentation with pain and disability once $O A$ changes are established. Our finding that the association with the TRPV1 gene is significant only with symptomatic OA suggests that consideration of the pain component of OA may aid discovery of stronger or more consistent genetic associations with $\mathrm{OA}$.

Patients seek medical help for symptoms and the main indication for knee arthroplasty, the most effective treatment for severe knee $\mathrm{OA}$, is pain rather than the degree of structural $\mathrm{ROA}$. It is therefore essential to understand the relationship between radiographic changes and pain in OA. Although there is a statistically significant association between knee ROA and pain, it has been reported that $<56 \%$ of subjects with moderate to severe knee ROA $(\mathrm{K} / \mathrm{L} \geq 3)$ actually experience regular pain. ${ }^{2-5}$ A US study analysed patients with frequent pain in only one knee, but who had bilateral radiographs and found that although increasing radiographic severity was significantly associated with knee pain, $46 \%$ of participants had the same radiographic grade in 
A

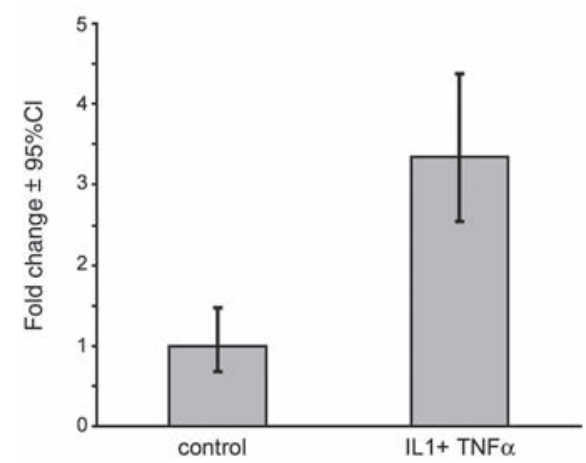

B

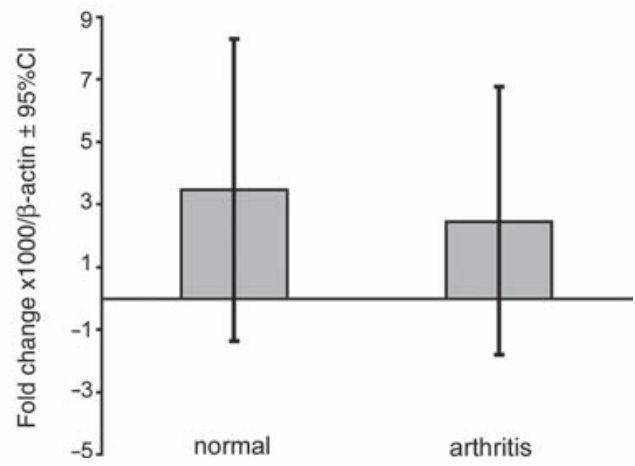

Figure 2 Gene expression of TRPV1 in joint tissues. (A) Cartilage explants from knee prosthesis surgery patients $(n=4)$ were cultured in Dulbecco's modified Eagle's medium/10\% fetal bovine serum for 10 days with or without tumour necrosis factor $\alpha$ (TNF $\alpha$ ) and interleukin 1 (IL-1; $10 \mathrm{ng} / \mathrm{ml}$ ) (triplicates). TRPV1 expression was determined by real-time quantitative PCR and analysed using the delta-delta Ct method standardised for independent biological replicates. Data are expressed as mean and $95 \% \mathrm{Cls}$. The difference between the control conditions and the cytokine cultured conditions yielded a $\mathrm{p}<0.0001$ in a Mann-Whitney $\mathrm{U}$ test. (B) Synovial biopsy specimens were analysed for expression of TRPV1 by real-time qualitative PCR and data expressed as mean and $95 \%$ Cls using relative expression compared with housekeeping gene $\beta$-actin $(n=3)$. The difference between the control conditions and the cytokine cultured conditions yielded a $p<0.0 .4$ in a Mann-Whitney $U$ test.

the symptomatic and asymptomatic knee and $10 \%$ had a worse radiographic grade in the asymptomatic knee. ${ }^{23}$ Recently it has been shown that OA patients with high pre-arthroplasty pain and a low pain thresholds have higher persistent pain postTKR for OA, reflecting the importance of an inherent predisposition to higher pain sensitivity. ${ }^{24}$ Genetic variation is one of the factors that can help explain the prevalence of pain in OA and this study adds new data in this direction. Understanding the molecular determinants of pain in knee OA has important clinical implications because current non-surgical treatments for knee OA offer limited pain relief with effect sizes of $<0.5$ for the most commonly used oral treatments when analysed in highquality trials. ${ }^{25} \mathrm{New}$ insights into the aetiopathogenesis of pain in patients with knee ROA may produce novel targets for new therapeutic interventions.

The genetic findings reported in this paper are supported by preclinical studies, which indicate an important role of TRPV1 in pain processing and, specifically, in experimental models of OA pain (see 'Introduction'). Indeed, TRPV1 expression by the primary afferent sensory fibre cell bodies innervating the joint is upregulated in a model of OA. ${ }^{10}$ This altered expression of $T R P V 1$ is likely to have an impact upon both peripheral and spi$\mathrm{nal}^{26}$ pain mechanisms in these models of OA pain. Since TRPV1 is expressed not only by primary afferent fibres, but also in joint tissues, it is possible that the genetic variation in the TRPV1 gene may influence structural damage associated with $O A$. This notion is supported by evidence for a contribution of primary afferent nociceptors to the progression of structural changes within the joint. In that study, degeneration of primary afferent nociceptors innervating the joint after intra-articular injection of capsaicin significantly decreased loss of bone volume and trabecular connectivity in a model of OA pain. ${ }^{27}$ Such data suggest that primary afferent nociceptors innervating the joint may also contribute to the progression of structural damage. Thus, in animal models of OA TRPV1 has complex contributions to the structural changes and pain associated with $\mathrm{OA}$, which may reflect the multiple sites at which TRPV1 is expressed within the joint and the pain pathways.

Our gene expression data in humans demonstrate that cytokine-induced stress to the articular cartilage increases expression of TRPV1. Interestingly, TNF $\alpha$ influences the phenotype and responses of primary afferent nociceptors-for example, TNF $\alpha$ increases the proportion of neurons that express TRPV1, ${ }^{28}$ and therefore contributes to the generation and maintenance of inflammatory joint pain. On this basis, TRPV1 may influence both peripheral pain sensitivity and structural damage in knee $\mathrm{OA}$. This is in agreement with recent clinical studies showing that the presence of knee pain is an independent predictor of longitudinal cartilage loss in patients with $\mathrm{OA}$ in addition to radiographic severity. ${ }^{29}$

On the other hand, we failed to observe any differences between expression of TRPV1 in normal and chronic inflammatory arthritis synovium. Earlier reports have demonstrated the expression of TRPV1 in synovial fibroblasts. We could not confirm upregulation by TNF $\alpha$ or IL-1 in our experimental system as was reported for a synovial cell line. However, in this cell line Kochucov et al also reported increased thermal and chemical responses of TRPV channels in response to TNF $\alpha .{ }^{20}$ In addition, Hu and coworkers associated TRPV1 with cell death in rat synoviocytes. ${ }^{30}$ Of note, the synovial samples used in our experiements were not of OA origin and further research in OA synovium is needed to confirm or disprove this lack of response to cytokines. Given that the cell bodies of the afferent fibres are in the dorsal root ganglia and that cartilage is not normally innervated, the altered expression in the chondrocytes would appear to suggest a role for TRPV1 in structural damage in $O A$. Further experiments investigating the role of TRPV1 in pain in OA and in joint damage in OA will help clarify this issue.

TRPV1, a member of the extended family of non-selective cationic TRP channels, is important in pain sensation. At the time of writing there are compounds approved, or under consideration, for regulatory approval which target this receptor to treat pain in large-joint OA. ${ }^{31}$ Our data suggest that a study of genetic factors that specifically influence the risk of symptomatic OA may point to therapeutic pathways for the treatment of OA.

Author affiliations 'Department of Twin Research, King's College London,

St Thomas' Hospital, London, UK

${ }^{2}$ Tigenix, Leuven, Belgium

${ }^{3}$ Academic Rheumatology, Nottingham City Hospital, University of Nottingham, Nottingham, UK

${ }^{4}$ Laboratory for Skeletal Development and Joint Disorders, Division of Rheumatology, KU Leuven, Leuven, Belgium 
${ }^{5}$ The Arthritis Research Institute of America, Clearwater, Florida, USA

${ }^{6}$ Menzies Research Institute, University of Tasmania, Hobart, Australia

${ }^{7}$ Respiratory \& Inflammation Research Area, AstraZeneca, Leicestershire, UK

${ }^{8}$ NIHR Musculoskeletal Biomedical Research Unit, University of Oxford, Oxford, UK

${ }^{9}$ Health Sciences Research Institute, Warwick Medical School University of Warwick, Coventry, UK

${ }^{10}$ MRC Lifecourse Epidemiology Unit, University of Southampton, Southampton General Hospital, Southampton, UK

${ }^{11}$ Department of Epidemiology and Preventive Medicine, Monash University Medical School, Melbourne, Australia

${ }^{12}$ Arthritis Research UK Pain Centre, School of Biomedical Sciences, University of Nottingham, Queen's Medical Centre, Nottingham, UK

Funding Supported by EC-FP7 programme grant 200800 TREAT-OA. AstraZeneca UK funded the GOAL study sample and data collection. The TwinsUK cohort is funded by the Wellcome Trust. The Hertfordshire Cohort Study (HCS) is supported by the Medical Research Council (UK) and the Oxford NIHR Musculoskeletal Biomedical Research Unit. The Clearwater Osteoarthritis Study has been funded by private donations. The Arthritis Research Campaign provided infrastructure support during the GOAL study, the collection of the Nottingham case-control study and for the Chingford Study and HCS. The Tasmanian Older Adult Cohort collection was funded by the National Health and Medical Research Council of Australia, Arthritis Foundation of Australia; Tasmanian Community Fund and a University of Tasmania Grant-Institutional Research Scheme.

Competing interest Dr. RA Maciewicz is employed by, owns stock and has patent applications for AstraZeneca. All other authors and organizations declare no conflict of interest.

Ethics approval This study was conducted with the approval of the Guy's and St Thomas' Trust and the Waltham Forest Trust ethics committees, research ethics committees of Nottingham City Hospital and North Nottinghamshire, East and North Hertfordshire ethical committees.

Provenance and peer review Not commissioned; externally peer reviewed.

\section{REFERENCES}

1. Lopez AD, Mathers CD, Ezzati M, et al. Global and regional burden of disease and risk factors, 2001: systematic analysis of population health data. Lancet 2006; 367:1747-57.

2. Pincus T, Block JA. Pain and radiographic damage in osteoarthritis. BMJ 2009;339:b2802.

3. Duncan R, Peat G, Thomas E, et al. Symptoms and radiographic osteoarthritis: not as discordant as they are made out to be? Ann Rheum Dis 2007:66:86-91.

4. Felson DT, Naimark A, Anderson J, et al. The prevalence of knee osteoarthritis in the elderly. The Framingham Osteoarthritis Study. Arthritis Rheum 1987;30:914-18

5. Lethbridge-Cejku M, Scott WW, Jr, Reichle R, et al. Association of radiographic features of osteoarthritis of the knee with knee pain: data from the Baltimore Longitudinal Study of Aging. Arthritis Care Res 1995;8:182-8.

6. Foulkes T, Wood JN. Pain genes. PLoS Genet 2008;4:e1000086.

7. Caterina MJ, Rosen TA, Tominaga M, et al. A capsaicin-receptor homologue with a high threshold for noxious heat. Nature 1999;398:436-41.

8. Basbaum AI, Bautista DM, Scherrer G, et al. Cellular and molecular mechanisms of pain. Cell 2009:139:267-84.

9. Huang J, Zhang X, McNaughton PA. Inflammatory pain: the cellular basis of heat hyperalgesia. Curr Neuropharmacol 2006;4:197-206.

10. Fernihough J, Gentry C, Bevan S, et al. Regulation of calcitonin generelated peptide and TRPV1 in a rat model of osteoarthritis. Neurosci Lett 2005; 388:75-80
11. Chu KL, Chandran P, Joshi SK, et al. TRPV1-related modulation of spinal neuronal activity and behavior in a rat model of osteoarthritic pain. Brain Res 2011:1369:158-66

12. Gavenis K, Schumacher C, Schneider U, et al. Expression of ion channels of the TRP family in articular chondrocytes from osteoarthritic patients: changes between native and in vitro propagated chondrocytes. Mol Cell Biochem 2009;321:135-43.

13. Idris Al, Landao-Bassonga E, Ralston SH. The TRPV1 ion channel antagonist capsazepine inhibits osteoclast and osteoblast differentiation in vitro and ovariectomy induced bone loss in vivo. Bone 2010;46:1089-99.

14. Engler A, Aeschlimann A, Simmen BR, et al. Expression of transient receptor potential vanilloid 1 (TRPV1) in synovial fibroblasts from patients with osteoarthritis and rheumatoid arthritis. Biochem Biophys Res Commun 2007;359:884-8.

15. Kim H, Neubert JK, San Miguel A, et al. Genetic influence on variability in human acute experimental pain sensitivity associated with gender, ethnicity and psychological temperament. Pain 2004;109:488-96.

16. Lötsch J, Flühr K, Neddermayer T, et al. The consequence of concomitantly present functional genetic variants for the identification of functional genotype-phenotype associations in pain. Clin Pharmacol Ther 2009;85:25-30.

17. Altman RD, Hochberg M, Murphy WA, Jr, et al. Atlas of individual radiographic features in osteoarthritis. Osteoarthr Cartil 1995;3 Suppl A:3-70.

18. Lories RJ, Derese I, De Bari C, et al. In vitro growth rate of fibroblast-like synovial cells is reduced by methotrexate treatment. Ann Rheum Dis 2003;62:568-71.

19. Willems E, Leyns L, Vandesompele J. Standardization of real-time PCR gene expression data from independent biological replicates. Anal Biochem 2008:379:127-9.

20. Kochukov MY, McNearney TA, Yin H, et al. Tumor necrosis factor-alpha (TNF-alpha) enhances functional thermal and chemical responses of TRP cation channels in human synoviocytes. Mol Pain 2009;5:49

21. Valdes AM, Spector TD, Doherty S, et al. Association of the DVWA and GDF5 polymorphisms with osteoarthritis in UK populations. Ann Rheum Dis 2009;68:1916-20

22. Valdes AM, Spector TD. The clinical relevance of genetic susceptibility to osteoarthritis. Best Pract Res Clin Rheumatol 2010;24:3-14.

23. Neogi T, Felson D, Niu J, et al. Association between radiographic features of knee osteoarthritis and pain: results from two cohort studies. BMJ 2009;339:b2844.

24. Lundblad $\mathbf{H}$, Kreicbergs $A$. Jansson KA. Prediction of persistent pain after total knee replacement for osteoarthritis. J Bone Joint Surg Br 2008;90:166-71.

25. Zhang W, Nuki G, Moskowitz RW, et al. OARSI recommendations for the management of hip and knee osteoarthritis: part III: Changes in evidence following systematic cumulative update of research published through January 2009. Osteoarthr Cartil 2010:18:476-99.

26. Puttfarcken PS, Han P, Joshi SK, et al. A-995662 [@-8-(4-methyl-5-(4(trifluoromethyl)phenyl)oxazol-2-ylamino)-1,2,3,4-tetrahydronaphthalen-2-ol], a novel, selective TRPV1 receptor antagonist, reduces spinal release of glutamate and CGRP in a rat knee joint pain model. Pain 2010;150:319-26.

27. Kalff KM, El Mouedden M, van Egmond J, et al. Pre-treatment with capsaicin in a rat osteoarthritis model reduces the symptoms of pain and bone damage induced by monosodium iodoacetate. Eur J Pharmacol 2010;641:108-13.

28. Schaible HG, von Banchet GS, Boettger MK, et al. The role of proinflammatory cytokines in the generation and maintenance of joint pain Ann N Y Acad Sci 2010;1193:60-9

29. Saunders J, Ding C, Cicuttini F, et al. Radiographic osteoarthritis and pain are independent predictors of knee cartilage loss: a prospective study. Intern Med J 2011;Published Online First: 8 Feb 2011. doi:10.1111/j.1445-5994.2011.02438.x.

30. Hu F, Sun WW, Zhao XT, et al. TRPV1 mediates cell death in rat synovial fibroblasts through calcium entry-dependent ROS production and mitochondrial depolarization. Biochem Biophys Res Commun 2008;369:989-93.

31. Medical News Today, July 2010. http://www.medicalnewstoday.com/ articles/195482.php (accessed 20 April 2011) 